\title{
Industrial Carbon Emission Efficiency in the Yangtze River Economic Belt and Its Influencing Factors
}

\author{
Yiqiong $\mathrm{Lu}^{1,2^{*}}, \mathrm{Miao} \mathrm{Li}^{3}$ \\ ${ }^{1}$ School of Environment and Natural Resources, Renmin University of China, Beijing 100086, China \\ ${ }^{2}$ Department of Work Safety and Environmental Protection, China Energy Investment Corporation Limited, Beijing 100011, \\ China \\ ${ }^{3}$ Development Research Center of the Ministry of Water Resources of P.R. China, Beijing 100038, China
}

Corresponding Author Email: yiqiong.lu@chnenergy.com.cn

https://doi.org/10.18280/ijdne.150104

Received: 2 June 2019

Accepted: 18 October 2019

\section{Keywords:}

the Yangtze River Economic Belt (YREB), industrial carbon emission efficiency, influencing factors, modified slack-based measure (mSBM)

\begin{abstract}
The industrial carbon emission reduction in the Yangtze River Economic Belt (YZEB) is of great significance to the Belt and Road Initiative in China. This paper builds an evaluation index system for industrial carbon emission efficiency, and measures the industrial carbon emission efficiencies of the 11 provincial administrative regions (provinces) in the YREB from 2002 to 2016, using the modified slack-based measure (mSBM). In addition, the author analyzed the influencing factors of the efficiency, and empirically tested the significance of each influencing factor by the Tobit model. The main conclusions are as follows: During the study period, the YREB provinces differed greatly in industrial carbon emission efficiency. Shanghai, Jiangsu and Zhejiang reached the optimal efficiency of one, while the other provinces failed to reach the optimal frontier, leaving the room for improvement. After dividing the YREB into three regions, it is learned that the downstream enjoyed the most efficient industrial carbon emission, which remained the same through the study area; the industrial carbon emission efficiencies in the midstream and the upstream were much lower than the upstream, but gradually improved with the elapse of time. On the influencing factors, the energy consumption structure and technical progress showed insignificant impacts, the ownership structure, foreign direct investment and environmental regulation greatly promoted the industrial carbon emission efficiency in the YREB, while the size of industrial enterprises obviously suppressed the efficiency.
\end{abstract}

\section{INTRODUCTION}

Since the reform and opening-up, China has made remarkable economic achievements. A huge amount of wealth has been created through the rapid development of all sectors in the national economy. Among them, the industrial sector has evolved into the main engine of China's economic growth, offering job opportunities to numerous people. However, the rapid industrial development faces a serious problem: the increasingly high emission of carbon dioxide $\left(\mathrm{CO}_{2}\right)$ and other greenhouse gases (GHGs). Currently, the industrial sector contributes over $85 \%$ of all carbon emission across the country. This proportion even surpasses $90 \%$ in many industrially developed provincial administrative regions (hereinafter referred to as provinces). The high industrial carbon emission poses a huge challenge to China's sustainable development, adding to the difficulty for the country to honor its promise, which was made on the UN Climate Change Conference 2009 in Copenhagen, to reduce the $\mathrm{CO}_{2}$ emission per unit of gross domestic product (GDP) by $40 \% \sim 45 \%$ before 2020 . China is still in the stage of high-speed industrialization. Being the main producer of $\mathrm{CO}_{2}$, the industrial sector is out of question the gist of $\mathrm{CO}_{2}$ emission reduction. The Yangtze River Economic Belt (YREB), the key to the implementation of the Belt and the Road Initiative, encompasses eleven provinces, including Shanghai, Jiangsu, Zhejiang, Anhui, Jiangxi, Hubei,
Hunan, Chongqing, Sichuan, Yunnan and Guizhou. With only $21 \%$ of China's landmass, the YREB accounts for over $40 \%$ of the population and economic output in the country. Meanwhile, more than one third of China's industrial carbon emission comes from the YREB. Hence, the YREB is not only the population center and economic hub, but also the main carbon emitter in China. Suffice it to say that China's success in fulfilling the target of carbon emission reduction directly hinges on how the YREB cuts down on its industrial carbon emission. In view of these issues, this paper attempts to determine the current level and influencing factors of the industrial carbon emission efficiency in the YREB.

With the growing awareness of the greenhouse effect and carbon emission reduction, more and more scholars at home and abroad have shifted their attention to the carbon emission efficiency. The existing studies on carbon emission efficiency mainly investigate the evaluation indices and the evaluation methods for carbon emission efficiency. The commonly used evaluation indices are either single factor evaluation indices or full factor evaluation indices. Typical examples of single factor evaluation indices include carbon productivity [1], $\mathrm{CO}_{2}$ emission per unit of GDP [2], carbon index [3] and per capita $\mathrm{CO}_{2}$ emission per unit of GDP [4]. The full factor evaluation indices are also known as carbon emission productivity [5] or total factor efficiency of carbon emission [6, 7]. Comparatively, single factor evaluation indices are easy to 
measure and quick to calculate. However, such indices are too simple to fully describe the generation of $\mathrm{CO}_{2}$. In fact, manmade carbon emission mostly originates from the consumption of fossil energy. The energy factor alone cannot lead to any output. This factor must be coupled with other elements like labor and capital to produce $\mathrm{CO}_{2}$. As a result, full factor evaluation indices are more popular than single factor ones in the evaluation of carbon emission efficiency. Data envelopment analysis (DEA) and stochastic frontier analysis (SFA) are the dominant ways to evaluate carbon emission efficiency. For instance, scholars like Zhou et al. [8] and Marklund and Samakovlis [9] employed the DEA to measure the carbon emission efficiencies in different countries. Herrala and Goel [10] constructed panel data and calculated carbon emission efficiency by the SFA. Compared with the SFA, the DEA is highly flexible in variable setting and data processing, and widely applied in many fields.

Despite the extensive studies on carbon emission efficiency, there are only a few reports on the industrial carbon emission reduction in the YREB. The relevant studies are often unfolded from the perspective of absolute amount of carbon emission. Taking the entire basin of the Yangtze River as a whole, Huang et al. [11] estimated the current status of industrial carbon emission reduction in the YREB, and analyzed the driving factors of industrial carbon emission reduction using the logarithmic mean divisa index (LMDI). Focusing on the construction of the YREB, Tian and Cheng [12] evaluated the industrial carbon emission efficiency of Jiangsu in 2000 2015 through the IPCC methodology for greenhouse gas inventories, and relied on the LMDI decomposition to detail industrial carbon emission in Jiangsu from economic scale, economic structure, energy intensity and energy structure. Both above two studies have discussed the industrial carbon emission reduction in the YREB from the angle of the absolute amount of carbon emission. Rarely has any scholar examined industrial carbon emission from the respective of efficiency, i.e. the industrial carbon emission efficiency. Zhao and Jiang [13] set up the 2006 2015 panel data on the 11 provinces of the YREB, and calculated the industrial carbon emission efficiency by three-stage DEA and the Malmquist index, revealing that the YREB has a low industrial carbon emission efficiency, the efficiency decreases from the eastern region, central region to the western region, and the efficiency gap between the 11 provinces has decreased since 2009

To sum up, the industrial carbon emission efficiency in the YREB has not been widely discussed, despite fruitful results on carbon emission efficiency at home and abroad. The relevant studies may have measured the YREB's industrial carbon emission efficiency, but failed to investigate the influencing factors of the efficiency. To solve these defects, this paper builds an evaluation index system for industrial carbon emission efficiency, and measures the industrial carbon emission efficiencies of the 11 provinces in the YREB, using the modified slack-based measure (mSBM). In addition, the author analyzed the action mechanism of influencing factors of the efficiency, and empirically tested the significance of each influencing factor by the Tobit model. The research findings provide reference for government at all levels in the YREB to formulate scientific and rational policies on carbon emission reduction.

\section{MATERIALS AND METHODS}

\section{$2.1 \mathrm{mSBM}$}

This paper adopts the mSBM: minimum distance to strong efficient frontier to measure industrial carbon emission efficiency. This method, proposed by Jahanshahloo et al. [14] and Aparicio et al. [15], measures the efficiency of an object based on the projection point with the minimum distance to the production frontier $\left(\mathrm{L}_{1}\right)$. In this research, the undesired output is introduced to the $\mathrm{mSBM}$, forming the $\mathrm{mSBM}$ with undesired output.

Let there be a complete production system of $\mathrm{n}$ decisionmaking units $D M U_{0}=\left(x_{0}, y_{0}^{g}, y_{0}^{b}\right)$, each of which requires $\mathrm{m}$ production factors and outputs $s_{1}$ unit(s) of desired output(s) and $s_{2}$ unit(s) of undesired output(s). For convenience, the input factors, desired output(s) and undesired output(s) are respectively expressed as the following vectors: $X=\left(x_{1}, x_{2}, \ldots, x_{n}\right) \in R_{+}^{m \times n}, Y^{g}=\left(y_{1}^{g}, y_{2}^{g} \ldots, y_{n}^{g}\right) \in R_{+}^{s_{1} \times n}$ and $Y^{b}=\left(y_{1}^{b}, y_{2}^{b} \ldots, y_{n}^{b}\right) \in R_{+}^{s_{2} \times n}$. Let $P^{t}(x)=\{(x, y): x$ can produce $y\}$ be the set of all possible inputs and outputs of $D M U_{0}$. Then, all the output units in the production set representing the strong efficient frontier can be denoted as $F^{s}(p)$. After the minimum distance to the production frontier $\left(L_{l}\right)$ is determined, the $\mathrm{mSBM}$ model can be expressed as:

$$
\begin{gathered}
(m S B M) \quad \min \left(\sum_{i=1}^{m} s_{i 0}^{-}+\sum_{r=1}^{s_{1}} s_{r 0}^{+}+\sum_{l=1}^{s_{2}} s_{l 0}^{-}\right)+M\left(\sum_{i=1}^{m} \bar{s}_{i 0}^{-}+\sum_{r=1}^{s_{1}} \overline{s_{r 0}^{+}}+\sum_{l=1}^{s_{2}} \overline{s_{l 0}^{-}}\right) \\
s_{i 0}^{-} \geq 0, i=1, \ldots, m \\
s_{r 0}^{+} \geq 0, r=1, \ldots, s_{1} \\
s_{l 0}^{-} \geq 0, l=1, \ldots, s_{2} \\
\max \left(\sum_{i=1}^{m} \overline{s_{i 0}^{-}}+\sum_{r=1}^{s_{1}} \overline{s_{r 0}^{+}}+\sum_{l=1}^{s_{2}} \overline{s_{l 0}^{-}}\right) \\
\text {s.t. } \sum_{j \in E_{c}} \lambda_{j} x_{i j}+\bar{s}_{i 0}^{-}=x_{i 0}-s_{i 0}^{-} \\
\sum_{j \in E_{c}} \lambda_{j} y_{i j}^{g}-\bar{s}_{r 0}^{+}=y_{i 0}^{g}+s_{r 0}^{+} \\
\sum_{j \in E_{c}} \lambda_{j} y_{i j}^{b}+\bar{s}_{l 0}^{-}=y_{i 0}^{b}-s_{l 0}^{-} \\
\lambda_{j} \geq 0, \bar{s}_{i 0}^{-} \geq 0, \bar{s}_{r 0}^{+} \geq 0, \overline{s_{l 0}} \geq 0
\end{gathered}
$$

where, $s_{i 0}^{-}, s_{r 0}^{+}, s_{l 0}^{-}, \bar{s}_{i 0}^{-}, \bar{s}_{r 0}^{+}$and ${\overline{s_{l 0}}}^{-}$are the relaxation terms of the input factors, desired output(s) and undesired output(s), representing the allowable magnitude of change of the input and output variables during the efficiency improvement; $m$ is a large positive number. Overall, the first part of the model, specifying the linear planning objectives, and the latter part, setting the linear constraints, combine into a typical two-layer linear programming structure. Compared with the traditional $\mathrm{SBM}$, the $\mathrm{mSBM}$ can minimize the change to the relaxation terms in efficiency improvement, and thus greatly save the cost of changes.

To verify the advantage of the $\mathrm{mSBM}$, both SBM and $\mathrm{mSBM}$ were adopted to measure the efficiency of a production system with 8 DMUs. The measured results of the two models are compared in Table 1, where $x_{1}, x_{2}$ and $x_{3}$ are three input variables, $y$ is the desired output, and $\mathrm{b}$ is the undesired output. For each DMU, the original values of the input or output are given in line 1 , the objective value is written before the 
Table 1. Comparison between SBM and mSBM in frequency measurement

\begin{tabular}{cccccccc}
\hline DMU & Model & Efficiency & $\mathbf{\mathbf { x } _ { 1 }}$ & $\mathbf{\mathbf { x } _ { 2 }}$ & $\mathbf{x} 3$ & $\mathbf{y}$ & $\mathbf{b}$ \\
\hline $\mathrm{C} 1$ & & & 28.1 & 4.6 & 31 & 12.6 & 6.3 \\
& SBM & 0.604 & $19.2(32 \%)$ & $2.5(46 \%)$ & $29.5(5 \%)$ & $12.6(0 \%)$ & $3.7(40 \%)$ \\
& $\mathrm{mSBM}$ & 0.897 & $25.6(9 \%)$ & $4.2(10 \%)$ & $31(0 \%)$ & $13.7(9 \%)$ & $6.3(0 \%)$ \\
$\mathrm{C} 4$ & & & 15 & 11.1 & 36.5 & 10.5 & 5.1 \\
& SBM & 0.564 & $15(0 \%)$ & $3.9(65 \%)$ & $26.8(26 \%)$ & $10.5(0 \%)$ & $2.7(47 \%)$ \\
& $\mathrm{mSBM}$ & 0.687 & $15(0 \%)$ & $8.8(20 \%)$ & $36.5(0 \%)$ & $12(15 \%)$ & $2.2(56 \%)$ \\
C8 & & & 19.8 & 4 & 23 & 9 & 5.1 \\
& SBM & 0.553 & $13.7(31 \%)$ & $1.8(55 \%)$ & $21(8 \%)$ & $9(0 \%)$ & $2.7(47 \%)$ \\
& mSBM & 0.885 & $19.8(0 \%)$ & $3.4(16 \%)$ & $22.3(3 \%)$ & $10(12 \%)$ & $5.1(0 \%)$ \\
\hline
\end{tabular}

Note: For the lack of space, only the results of DMUs with efficiency less than 1 are listed in Table 1.

As shown in Table 1, none of the three DMUs achieved the optimal efficiency, but the two models differed in the amplitude of improvement towards the target efficiency. Taking DMU C1 for instance, the target efficiency could be reached under the SBM by improving the input variables $x_{1}, x_{2}$ and $x_{3}$ by $32 \%, 46 \%$ and $5 \%$, respectively, and improving the output variable $b$ by $40 \%$. Meanwhile, the target efficiency could be realized under the mSBM by improving the input variables $x_{1}$ and $x_{2}$ by $9 \%$ and $10 \%$, respectively, and improving the output variable $y$ by $9 \%$. To optimize the efficiency of DMU C1, the input and output variables need to be improved by a much smaller amplitude under the mSBM than under the SBM. The same results were observed on DMUs C4 and C8.

The comparison shows that $\mathrm{mSBM}$ can optimize the target efficiency of DMUs more easily than the SBM, because it requires a smaller amplitude in improving the input and output variables. In reality, the input factors and output results should be adjusted to optimize the efficiency of economic and production activities. The adjustments incur a certain amount of cost. To optimize the resource allocation, the efficiency should be improved with the smallest adjustment cost, making it easier for decision-makers to prepare the most suitable production plan. In this respect, the mSBM enjoys a great advantage over the SBM in efficiency measurement.

\subsection{Evaluation indices for industrial carbon emission efficiency}

In this paper, the industrial carbon emission efficiency is a concept covering all kinds of factors related to industrial carbon emission, ranging from economy, energy to environment. The term "efficiency" refers to the proportional relationship between input factors and output results, that is, how many production factors is needed to output a certain result. On this basis, the industrial carbon emission efficiency is defined as the ratio between the actual output to the optimal output per unit of industrial $\mathrm{CO}_{2}$ emission under a fixed amount of input factors (e.g. labor, capital and energy)[6, 16]. The ratio is negatively correlated with the gap between the actual output and the optimal output per unit of industrial $\mathrm{CO}_{2}$ emission, and positively correlated with industrial carbon emission efficiency.

According to the above "all factor" definition of industrial carbon emission efficiency, the evaluation index system should encompass multiple input factors and output results. According to Zhou et al. and Wang [17, 18], the author established an evaluation index system for industrial carbon emission efficiency containing three inputs, industrial labor, industrial capital stock and industrial energy input, and two outputs, total industrial output and industrial $\mathrm{CO}_{2}$ emission. The input and output variables are detailed as follows.

\section{(1) Industrial labor}

Following the common practice, this paper characterizes the labor force with the number of employees. Specifically, the industrial labor is expressed as the annual mean number of industrial employees in the YREB provinces (unit: 10,000 people).

\section{(2) Industrial capital stock}

Industrial capital, an essential input for production activities in the industrial sector, is the precondition for enterprises to purchase equipment, hire labor and conduct technical R\&D. Since the data on the fixed capital stock cannot be directly obtained from statistical yearbooks, the industrial fixed capital stock was estimated by the perpetual inventory method (PIM), which requires data on the depreciation rate of regional industrial capital and the estimated initial industrial capital stock. Nonetheless, this estimation method may have some deviations due to the limited statistical data and numerous estimations. To prevent the deviations, this paper takes net value of industrial fixed asset as the regional industrial capital stock. To avoid the distortion induced by price inflation, the net value of industrial fixed asset was deflated to the comparable price of 2002, using the fixed price index of each YREB province.

\section{(3) Industrial energy input}

The industrial energy input refers to the terminal consumption of industrial energies, i.e. the total consumption of such energies as raw coal, natural gas, coke, diesel, gasoline, etc. For convenience, the different energies were converted into the total industrial energy input (unit: 10,000 tons of standard coal).

\section{(4) Total industrial output}

The total industrial output is the desired output in this research. The relevant statistical yearbooks only provide the total output of the industrial enterprises above designated size in each region (the current year's price), which is a nominal value of industrial output. To eliminate the inflationary effect of nominal price, the nominal industrial output was converted into the actual industrial output with the annual industrial product price index, using 2002 as the base year.

\section{(5) Industrial $\mathrm{CO}_{2}$ emission}

The industrial $\mathrm{CO}_{2}$ emission is the undesired output of this 
research. Up to $90 \%$ of industrial $\mathrm{CO}_{2}$ is emitted from the combustion of fossil energies, with a very small portion from other processes (e.g. lime calcination into cement). For simplicity, the industrial $\mathrm{CO}_{2}$ emission was considered as purely produced from fossil energy consumption in industrial production. Due to the lack of specific data in relevant statistical yearbooks, the industrial $\mathrm{CO}_{2}$ emission was estimated by the method in the IPCC 2006 Guidelines for National Greenhouse Gas Inventories: $\mathrm{CO}_{2}=\sum_{i=1}^{n} E_{i} \times N C V_{i} \times C E F_{i} \times C O F_{i} \times(44 / 12) \quad$, where $\mathrm{CO}_{2}$ is the estimated industrial $\mathrm{CO}_{2}$ emission, $i$ is the type of industrial energy being consumed, $E$ is the industrial energy consumption calculated based on the physical quantity (unit: 10,000 standard coal), NCV , CEF and $C O F$ are net energy calorific value, carbon emission coefficient and carbon oxidation factor, respectively, and 44 and 12 are the molecular weights of $\mathrm{CO}_{2}$ and carbon, respectively. The standard coal coefficients were cited from Chinese national standard (GB2589-81), and the values of net energy calorific value, carbon emission coefficient and carbon oxidation factor were released by Energy Research Institute, National Development and Reform Commission.

\subsection{Tobit model}

After determining the industrial carbon emission efficiency of the YREB, it is necessary to identify the main influencing factors of the efficiency and the degree of influence of each factor, before speed up the industrial carbon emission reduction in the YREB. The industrial carbon emission efficiency was derived by the mSBM, a DEA strategy, and thus fell between the lower limit of zero and the upper limit of one. If the empirical model is regressed by the traditional least squares method, the regression result may be biased towards zero, resulting in a huge deviation in the estimation result [19]. To eliminate the bias, this paper selects the Tobit model, a.k.a. the censored regression model, proposed by the famous economist Tobit in 1958. During construction, this model fully considers the $[0,1]$ constraint of the dependent variable, and thus adapts well to the requirement that the independent variable should fall between zero and one.

Many scholars suggested that industrial carbon emission efficiency is greatly affected by structural factors like the size of industrial enterprises, the structure of light and heavy industries, energy consumption structure, and ownership structure [20]. Meanwhile, some scholars noted the important influence of external institutional factors (e.g. opening-up and technical progress) over industrial carbon emission and its efficiency [21, 22]. As China advocates the concept of green development, a growing number of scholars start to highlight the impact of the government's environmental policies on industrial carbon emission reduction. Therefore, environmental regulation is another impactor of industrial carbon emission efficiency [23]. Inspired by these studies, this paper sets up an empirical model to analyze the influencing factors of industrial carbon emission efficiency in the YREB, considering the following internal and external environmental factors that affect the efficiency: the size of industrial enterprises, ownership structure, energy consumption structure, technical progress, foreign direct investment and environmental regulation. The meanings of the six factors are detailed below.

(1) Size of industrial enterprises (SIZ)
The industrial sector consists of various industries, which differ greatly in the size of enterprises. In general, large industrial enterprises are less flexible than small ones in the adjustment of input factors like energy, capital and labor and output products. Thus, small industrial enterprises often enjoy better production efficiency than large industrial enterprises in a general competitive market. With a high production efficiency, the enterprises tend to make intensive use of energy, capital and labor, which is conducive to carbon emission reduction. As a result, the larger an industrial enterprise, the lower the production efficiency, and the harder it is to improve industrial carbon emission efficiency. Referring to Shao et al.'s definition of scale variable [24], this paper defines the size of industrial enterprises as the quotient of the total industrial output and the number of industrial enterprises.

\section{(2) Ownership structure (SOE)}

The industrial enterprises in China can be divided into stateowned and non-state-owned by the nature of ownership. The relevant research has shown that, under market competition, enterprise with different ownership structures resort to different incentive mechanisms. The difference not only directly bears on the daily production, but also impacts the enterprise behaviors of energy conservation and environmental protection. As a result, the ownership structure affects the low-carbon transformation of the entire industry, and thus the industrial carbon emission efficiency in each region. Drawing on Jin et al.'s definition of enterprise ownership structure [25], this paper defines the ownership structure as the ratio of industrial output of state-owned and state-controlled enterprises above designated size to total industrial output.

\section{(3) Energy consumption structure (ECS)}

The $\mathrm{CO}_{2}$ emitted in the industrial sector is normally the direct product of industrial energy consumption. Hence, the industrial energy consumption structure must have a significant impact ton industrial carbon emission. The traditional fossil energies like coal and oil are typical highcarbon energies, compared with clean energies like bioenergy, hydro energy, wind energy and nuclear energy. China has long been the world's leading coal producer and consumer. Unsurprisingly, coal dominates the energy consumption structure in the YREB provinces. It is meaningful to explore the impact of this particular structure on industrial carbon emission efficiency. Inspired by Huang and Liu [26], this paper characterizes the energy consumption structure as the ratio of industrial coal consumption to the total industrial energy consumption in each YREB province.

\section{(4) Technical Progress (TEG)}

The proliferation and adoption of advanced technologies is fundamental to industrial carbon emission reduction in each region. For one thing, technical progress helps enterprises upgrade production equipment, and save production factors like energy, thus reducing $\mathrm{CO}_{2}$ emission. For another, the application of advanced technology prompt enterprises to purchase advanced energy-saving equipment, which also promote carbon reduction. Thus, regional technical progress can promote the industrial carbon emission efficiency. Based on the research of Wang and $\mathrm{Qu}$ [27], this paper describes technical progress as the ratio of the internal expenditure on science and technology activities of large and medium-sized industrial enterprises to the total industrial output 


\section{(5) Foreign direct investment (FDI)}

With the deepening of the opening-up policy in China, the exchanges with the international market have become an inseparable part of the regional economy. Many local governments have rolled out favorable policies to attract investment, drawing a huge amount of foreign capital. The foreign capital enables enterprises to expand their production scale, leading to greater $\mathrm{CO}_{2}$ emission. Meanwhile, most foreign investors bring advanced technologies, equipment and management experience, which push up production efficiency and reduce carbon emission. Overall, the foreign direct investment has an uncertain impact on industrial carbon emission efficiency. According to the results of Wang and Jiang [28], this paper measures foreign direct investment as the ratio of the actually used foreign direct investment (converted from USD to RMB) to GDP of each YREB province.

\section{(6) Environmental regulation (ERS)}

Since the Chinese government announced the five concepts of development (i.e. innovation, coordination, greenness, openness and sharing), the country has attached greater importance to the green, low-carbon development of the national economy, especially the industrial sector. The regional environmental regulation is playing an increasingly important role in industrial green and low-carbon development. The sound environmental regulation at the local level helps to effectively monitor the pollutant emission by enterprises, and increase the cost of pollutant emission, forcing enterprises to improve their capabilities of energy conservation and reduce their $\mathrm{CO}_{2}$ emission. In other words, the government can stimulate the emission reduction among enterprises by formulating environmental regulation policies, which will promote the industrial carbon emission efficiency. Considering the research by Wang and Zhang [29], this paper depicts environmental regulation as the ratio of industrial investment on environmental pollution control to the total industrial output.

According to the above influencing factors of industrial carbon emission efficiency in the YREB, this paper sets up a Tobit model with industrial carbon emission efficiency as the explained variable, and the size of industrial enterprises, ownership structure, energy consumption structure, technical progress, foreign direct investment and environmental regulation as the explanatory variables.

$$
\begin{aligned}
& T E_{i t}^{*}=\alpha+\beta_{1} S I Z_{i t}+\beta_{2} S O E_{i t}+\beta_{3} E C S_{i t} \\
& +\beta_{4} T E G_{i t}+\beta_{5} F D I_{i t}+\beta_{6} E R S_{i t}+\varepsilon \\
& \left\{\begin{array}{l}
T E_{i t}=T E_{i t}^{*}\left(\text { If } T E_{i t}^{*}<1\right) \\
\left.T E_{i t}=1 \quad \text { (If } T E_{i t}^{*} \geq 1\right)
\end{array}\right.
\end{aligned}
$$

where, $T E_{i t}^{*}$ is industrial carbon emission efficiency, the explained variable of the model; $S I Z_{i t}$ is the size of industrial enterprises, the ratio of the total industrial output to the number of industrial enterprises; $S O E_{i t}$ is the ownership structure, the ratio of industrial output of state-owned and state-controlled enterprises above designated size to total industrial output; $E C S_{i t}$ is the energy consumption structure, the ratio of industrial coal consumption to the total industrial energy consumption; $T E G_{i t}$ is the technical progress, the ratio of the internal expenditure on science and technology activities of large and medium-sized industrial enterprises to the total industrial output; $F D I_{i t}$ is the foreign direct investment as the ratio of the actually used foreign direct investment (converted from USD to RMB) to GDP of each YREB province; $E R S_{i t}$ is the environmental regulation, the ratio of industrial investment on environmental pollution control to the total industrial output; $\varepsilon$ is a random perturbation term.

\subsection{Data sources}

Considering the data availability and completeness of the input and output variables in the mSBM and the influencing factors in the Tobit model, this paper takes the panel data in 2002 2016 of the 11 YREB provinces as the research object. The data on industrial labor, net value of industrial fixed asset, terminal consumption of industrial energy, total industrial output, the number of industrial enterprises, industrial coal consumption, the internal expenditure on science and technology activities of large and medium-sized industrial enterprises, foreign direct investment, and industrial investment on environmental pollution control, were all extracted from the China Industry Statistical Yearbook, China Statistical Yearbook, China Energy Statistical Yearbook, China Science and Technology Statistical Yearbook, China Environmental Yearbook, and local statistical yearbooks released by the YREB provinces.

\section{RESEARCH RESULTS}

\subsection{Static temporal variation in the industrial carbon emission efficiency}

Based on the proposed evaluation index system, the data on the input and output variables were imported to the MaxDEA to obtain the industrial carbon emission efficiency of each YREB province in 2002 2016. The obtained results in Table 2 show that the YREB provinces had great differences in industrial carbon emission efficiency. Based on the efficiency value, the eleven provinces can be divided into four levels.

Shanghai, Jiangsu and Zhejiang belonged to the first level through the study period. Their industrial carbon emission efficiencies were consistently at one, i.e. the most optimal value. The three provinces reached the optimal frontier of industrial carbon emission efficiency for two reasons: (1) Being the most developed economics in the YREB, the three provinces started early in industrialization and lead the country in industrial output; (2) The industrial enterprises in these provinces boast strong emission reduction capabilities, thanks to their advanced industrial production technologies and emphasis on the R\&D and popularization of low-carbon technologies.

With industrial carbon emission efficiencies between 0.6 and 1, Chongqing, Anhui and Jiangxi ranked on the second level. Chongqing, as the largest municipality directly under the central government, has enjoyed preferential policies from the state government and vigorously attracted investment. Thus, this province maintained a high growth rate of industry and high level of industrial output. Anhui and Jiangxi are both located in the midstream of the Yangtze River. The two provinces have achieved relatively fast economic growth in recent years, which promoted the industrial output. The increased output, coupled with the use of advanced industrial technologies, have contributed to their capabilities of industrial carbon emission reduction.

Hunan, Sichuan and Hubei were categorized to the third 
level, with industrial carbon emission efficiencies within $0.5 \sim 0.6$ in the study period. The moderate efficiencies were relatively far from the optimal frontier. Sichuan lies in the upstream of the Yangtze River, while Hunan and Hubei belong to the midstream. Despite their rapid industrial growth, the three provinces witnessed high industrial $\mathrm{CO}_{2}$ emission in recent years, due to the high proportion of heavy industry. That is why they exhibited a relatively low industrial carbon emission efficiency.

Yunnan and Guizhou, failing to surpass 0.5 in industrial carbon emission efficiency, were at the bottom level. The two provinces are backward regions in China in terms of economic development, and faced with slow industrial development. Compared with the other YREB provinces, Yunnan and Guizhou have low industrial output and poor industrial technologies, leading to a weak emission reduction capacity of the local industrial sector.

In summary, the YREB provinces differed greatly in industrial carbon emission efficiency. The provinces in the downstream were generally more efficient than those in the upstream and midstream. Under the Belt and Road Initiative, the industrial carbon emission reduction in the upstream and midstream must be highlighted to turn the YREB into the demonstration zone of ecological civilization in China.

Table 2. Industrial carbon emission reduction of each YREB province in 2002 2016

\begin{tabular}{|c|c|c|c|c|c|c|c|c|c|c|c|}
\hline Year & Shanghai & Jiangsu & Zhejiang & Chongqing & Anhui & Jiangxi & Hunan & Sichuan & Hubei & Yunnan & Guizhou \\
\hline 2002 & 1 & 1 & 1 & 0.6651 & 0.4778 & 0.5373 & 0.4608 & 0.4350 & 0.5407 & 0.4788 & 0.3916 \\
\hline 2003 & 1 & 1 & 1 & 0.6862 & 0.4753 & 0.5384 & 0.4601 & 0.4353 & 0.4720 & 0.4412 & 0.3658 \\
\hline 2004 & 1 & 1 & 1 & 0.6512 & 0.5057 & 0.5312 & 0.4922 & 0.4595 & 0.4463 & 0.4339 & 0.3669 \\
\hline 2005 & 1 & 1 & 1 & 0.7026 & 0.5703 & 0.5434 & 0.5013 & 0.5164 & 0.4487 & 0.4540 & 0.3731 \\
\hline 2006 & 1 & 1 & 1 & 0.7061 & 0.5736 & 0.5509 & 0.5141 & 0.5326 & 0.4572 & 0.4489 & 0.3698 \\
\hline 2007 & 1 & 1 & 1 & 0.7192 & 0.5668 & 0.5801 & 0.5257 & 0.5472 & 0.4563 & 0.4368 & 0.3671 \\
\hline 2008 & 1 & 1 & 1 & 0.7066 & 0.5616 & 0.6004 & 0.5431 & 0.5543 & 0.4756 & 0.4206 & 0.3593 \\
\hline 2009 & 1 & 1 & 1 & 0.7694 & 0.6118 & 0.6503 & 0.5537 & 0.5727 & 0.5122 & 0.4241 & 0.3626 \\
\hline 2010 & 1 & 1 & 1 & 0.7576 & 0.6382 & 0.6639 & 0.5687 & 0.5577 & 0.5437 & 0.3880 & 0.3428 \\
\hline 2011 & 1 & 1 & 1 & 0.8293 & 0.6932 & 0.6651 & 0.6164 & 0.5963 & 0.5678 & 0.3908 & 0.3690 \\
\hline 2012 & 1 & 1 & 1 & 0.8138 & 0.6877 & 0.6551 & 0.6023 & 0.5583 & 0.6159 & 0.3923 & 0.3622 \\
\hline 2013 & 1 & 1 & 1 & 0.8431 & 0.7423 & 0.6736 & 0.6288 & 0.5605 & 0.6272 & 0.3920 & 0.4030 \\
\hline 2014 & 1 & 1 & 1 & 0.8959 & 0.7670 & 0.6873 & 0.6442 & 0.5843 & 0.6428 & 0.3749 & 0.4283 \\
\hline 2015 & 1 & 1 & 1 & 0.9228 & 0.7786 & 0.7031 & 0.6296 & 0.6245 & 0.6456 & 0.3841 & 0.4736 \\
\hline 2016 & 1 & 1 & 1 & 0.9125 & 0.7900 & 0.7241 & 0.6329 & 0.6321 & 0.6459 & 0.3925 & 0.4955 \\
\hline Mean & 1 & 1 & 1 & 0.7721 & 0.6293 & 0.6203 & 0.5583 & 0.5444 & 0.5399 & 0.4169 & 0.3887 \\
\hline
\end{tabular}

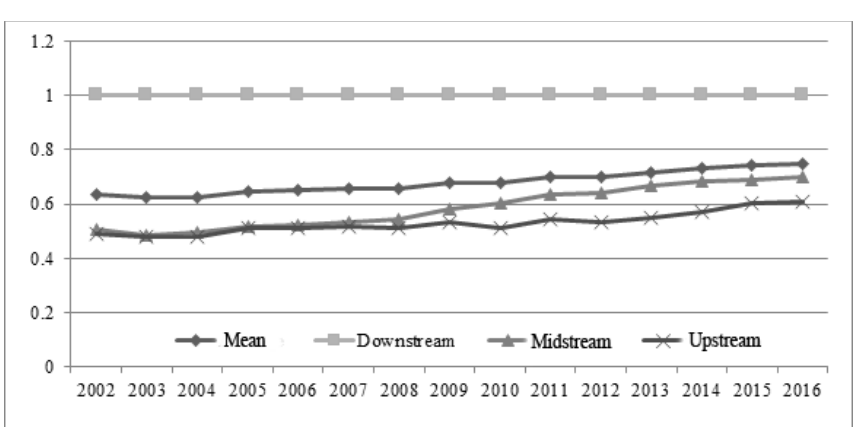

Figure 1. Industrial carbon emission efficiencies of the YREB, the upstream, the midstream and the downstream

Figure 1 illustrates the trends of industrial carbon emission efficiencies in the upstream, midstream and downstream of the YREB. It can be seen that, the industrial carbon emission efficiency of the downstream remained at one, i.e. the optimal frontier, showing no variation through the study period. Meanwhile, the midstream and the upstream had basically the same trend of industrial carbon emission efficiency. Before 2008, the efficiencies of the midstream and upstream had no significant changes; after 2008, the efficiencies were slowly on the rise, and the rising speed of the midstream was slightly higher than that of the upstream. Judging by the mean industrial carbon emission efficiency, the three regions exhibited pronounced differences. The mean value of the downstream stood at one, far greater than the mean value of the YREB (0.6791). The mean values of the midstream and the upstream were respectively 0.5869 and 0.5305 , both of which were lower than the mean value of the YREB. By industrial carbon emission efficiency, the three regions of the YREB ranked in descending order as the downstream, the midstream and the upstream. This means the industrially developed downstream was far more efficient in industrial carbon emission than the midstream and the upstream.

\subsection{Analysis on Tobit results}

The Tobit model in equation (2) was regressed on STATA12.0 to disclose the impacts of the six influencing factors on the industrial carbon emission efficiency in the YREB. The regression results are listed in Table 3.

Table 3. Regression results of Tobit model

\begin{tabular}{cccc}
\hline Variable & Coefficient & T-value & P-value \\
\hline SIZ & $-0.0848^{* * *}$ & -4.94 & 0.000 \\
SOE & $0.6404^{* * *}$ & -6.27 & 0.000 \\
$E C S$ & -0.0044 & -0.79 & 0.429 \\
$T E G$ & 2.6444 & 0.72 & 0.473 \\
$F D I$ & $2.4033^{* *}$ & 2.23 & 0.027 \\
ERS & $16.9665^{* * *}$ & 13.02 & 0.000 \\
L- likelihood & & -23.5178 & \\
\hline
\end{tabular}

The size of industrial enterprises (SIZ) exerted a negative impact on industrial carbon emission efficiency at the significance level of $1 \%$, indicating that the growing size of enterprise hinders the improvement of industrial carbon emission efficiency. This agrees with our previous expectation, and reflects the heterogeneity between industrial enterprises of different sizes in the YREB provinces. Most large industrial enterprises belong to the heavy industry, which is featured by high pollution and heavy emission. These enterprises have lots of excess capacity and emit a large amount of $\mathrm{CO}_{2}$. By contrast, the small industrial enterprises, mostly falling into the light 
industry, enjoy high production efficiency and low $\mathrm{CO}_{2}$ emission. To sum up, the larger the industrial enterprises, the higher the $\mathrm{CO}_{2}$ emission, and the poorer the efficiency of industrial carbon emission.

The ownership structure ( $S O E$ ) had a positive estimated coefficient and passed the test at the significance level of $1 \%$. This means the ratio of state-owned and state-controlled enterprises in the industrial sector is positively correlated with the industrial carbon emission efficiency. The result also agrees with our previous expectation. It can be seen that stateowned and state-controlled enterprises adhere more strictly to national policies than private enterprises. Currently, China is vigorously promoting green development. The state-owned and state-controlled enterprises will pioneer in energy conservation and emission reduction. Their exemplary effect will boost the awareness of environmental protection and promote low-carbon transition, pushing up the industrial carbon emission efficiency across the region.

The energy consumption structure (ECS ) had a negative impact on industrial carbon emission efficiency, but failed to pass the significance test. The possible reason is as follows: The dominance of coal in the energy consumption $(>70 \%)$ of the YERB provinces has been dwindling annually, as China endeavors to forge a green energy industry belt along the Yangtze River. The YERB provinces have adopted strategies to develop clean energies, and encouraged the industrial sector to replace traditional fossil energies with clean energies. The changing energy consumption structure is beneficial to the energy-saving and emission reduction of the industrial sector. That is why the energy consumption structure failed to significantly affect the industrial carbon emission efficiency.

The technical progress ( TEG ) had a positive impact on industrial carbon emission efficiency, but failed to pass the significance test. This is attributable to the resource allocation of R\&D investment in industrial enterprises. According to Acemoglu et al. [30], the original R\&D activities of industrial enterprises focus on clean or pollution technologies, and the R\&D of either technology has a certain coherence. If an industrial enterprise diverts a huge sum of $R \& D$ fund to pollution technology, the pollutant emission will become more serious. As a result, the governments at all levels in the YREB must guide the enterprises to invest more innovative resources to the $\mathrm{R} \& \mathrm{D}$ of environmentally-friendly production technologies.

The foreign direct investment (FDI) had a positive estimated coefficient and passed the test at the significance level of $5 \%$, indicating that opening-up is conducive to industrial carbon emission efficiency. This fully demonstrates that the strengthening of foreign investment promotes industrial carbon emission reduction, and the effect of foreign capital on $\mathrm{CO}_{2}$ emission reduction exceeds the scale effect. It is clearly stipulated in the Outline of Yangtze River Economic Belt Development Plan that, the YREB should create a new opening-up pattern and more favorable conditions for foreign direct investment. Statistics show that the foreign direct investment in the YREB increased 4.10 times in 15 years, from USD 23.771 billion in 2002 to 121.261 billion in 2016 .

The environmental regulation ( $E R S$ ) exhibited a positive impact on industrial carbon emission efficiency at the significance level of $1 \%$, which signifies the promotional effect of strong environmental regulation on the efficiency. This also shows that a single enterprise, lured by economic interests, often expands the production scale to maximize the profit at the cost of environment. The emphasis on economic interests over environmental benefits cause great damages to the environment. To solve the problem, the government must lay down compulsory environmental regulations that greatly increase the pollutant emission cost, forcing the enterprises to reduce various pollutants, including the $\mathrm{CO}_{2}$.

\section{DISCUSSION}

The YREB is the key to the implementation of the Belt and Road Initiative. The Chinese government has made it clear that the YREB provinces must take ecology as the priority and pursue green development, and place environmental protection over largescale development. Against this backdrop, how to achieve green, low-carbon development becomes a critical issue to the YREB. To promote the sustainable development of the YREB, the industrial sector, as the driving engine of national economy, should forcefully reduce its carbon emission. However, the YREB covers several industrial hubs, such as the Yangtze River Delta, Wuhan Metropolitan Area, and Chengdu-Chongqing Economic Circle. The heavy industry is developed across the YREB, bringing a consistently high $\mathrm{CO}_{2}$ emission. The governments at all levels of the YREB are responsible for accelerating the reduction of industrial carbon emission. Thus, it is very meaningful to measure the industrial carbon emission efficiency of each YREB province accurately, and discuss the external influence factors of the efficiency. The findings of this paper offer the insights into the industrial carbon emission levels of the YREB provinces, and provide reference for government at all levels to formulate scientific and rational policies on carbon emission reduction.

\section{CONCLUSIONS}

This paper builds an evaluation index system for industrial carbon emission efficiency, and measures the industrial carbon emission efficiencies of the 11 provinces in the YREB, using the mSBM. In addition, the author analyzed the influencing factors of the efficiency, and empirically tested the significance of each influencing factor by the Tobit model. The main conclusions are as follows:

During the study period, the YREB provinces differed greatly in industrial carbon emission efficiency. Shanghai, Jiangsu and Zhejiang reached the optimal efficiency, Chongqing, Anhui and Jiangxi had a certain distance from the optimal frontier, and the other provinces failed to achieve desirable industrial carbon emission efficiencies. After dividing the YREB into three regions, it is learned that the downstream enjoyed the most efficient industrial carbon emission, which remained the same through the study area; the industrial carbon emission efficiencies in the midstream and the upstream were much lower than the upstream, but gradually improved with the elapse of time. Both internal structural factors and external institution and policy factors affect the industrial carbon emission efficiency. Specifically, the energy consumption structure and technical progress showed insignificant impacts, the ownership structure, foreign direct investment and environmental regulation greatly promoted the industrial carbon emission efficiency in the YREB, while the size of industrial enterprises obviously suppressed the efficiency. 


\section{REFERENCES}

[1] Kaya, Y., Yokobori, K. (1993). Global environment, energy, and economic development held at the United Nations University, Tokyo.

[2] Sun, J.W. (2005). The decrease of $\mathrm{CO}_{2}$ emission intensity is decarbonization at national and global levels. Energy Policy, 33(8): 957-978. https://doi.org/10.1016/j.enpol.2003.10.023

[3] Mielnik, O., Goldemberg, J. (1999). Communication the evolution of the "Carbonization Index" in developing countries. Energy Policy, 27(5): 307-308. https://doi.org/10.1016/S0301-4215(99)00018-X

[4] Zhang, Y., Zhang, J.Y., Yang, Z.F., Li, S.S. (2011). Regional differences in the factors that influence China's energy-related carbon emissions and potential mitigation strategies. Energy Policy, 39(12): 7712-7718. https://doi.org/10.1016/j.enpol.2011.09.015

[5] Kaneko, S., Managi, S. (2004). Environmental productivity in China. Economics Bulletin, 7(2): 1-10.

[6] Wang, B., Wu, Y.R., Yan, P.F. (2010). Environmental efficiency and environmental total factor productivity growth in China's regional economies. Economic Research Journal, 45(5): 95-109.

[7] Reinhard, S., Knox Lovell, C.A., Thijssen, G.J. (2000). Environmental efficiency with multiple environmentally detrimental variables; estimated with SFA and DEA. European Journal of Operational Research, 121(2): $287-$ 303. https://doi.org/10.1016/s0377-2217(99)00218-0

[8] Zhou, P., Ang, B.W., Han, J.Y. (2010). Total factor carbon emission performance: A malmquist index analysis. Energy Economics, 32(1): 194-201. https://doi.org/10.1016/j.eneco.2009.10.003

[9] Marklund, P.O., Samakovlis, E. (2007). What is driving the EU burden-sharing agreement efficiency or equity? Journal of Environmental Management, 85(2): 317-329. https://doi.org/10.1016/j.jenvman.2006.09.017

[10] Herrala, R., Goel, R.K. (2012). Global $\mathrm{CO}_{2}$ efficiency: Country-wise estimates using a stochastic cost frontier. Energy Policy, 45(7): 762-770. https://doi.org/10.1016/j.enpol.2012.03.007

[11] Huan, G.H., Liu, C.J., Li, X.P. (2016). Industrial carbon emissions and its driving factors in the Yangtze River Economic Belt. Jiangxi Social Sciences, 2016(8): 54-62.

[12] Tian, Z., Cheng, F. (2017). Study on industrial carbon emission estimation and its influencing factors in Jiangsu Province under the construction of Yangtze River Economic Belt. Ecological Economy, 33(12): 24-27.

[13] Zhao, S., Jiang, X.C. (2018). Research on the performance of industrial carbon emission in the Yangtze river economic belt based on the three-stage DEA and malmquist index. Journal of Finance and Economics Theory, 2018(4): 68-77. https://doi.org/10.3969/j.issn.1004-5295.2018.04.008

[14] Jahanshahloo, G.R., Vakili, J., Zarepisheh, M. (2012). A linear bilevel programming problem for obtaining the closest targets and minimum distance of a unit from the strong efficient frontier. Asia-Pacific Journal of Operational Research, 29(2): 1-19. https://doi.org/10.1142/s021759591250011x

[15] Aparicio, J., Ruiz, J.L., Sirvent, I. (2007). Closest targets and minimum distance to the pareto-efficient frontier in DEA. Journal of Productivity Analysis, 28(3): 209-218. https://doi.org/10.2307/41770285
[16] Zhou, P., Ang, B.W., Poh, K.L. (2008). Measuring environmental performance under different environmental DEA technologies. Energy Economics, 30(1): 1 -14 . https://doi.org/10.1016/j.eneco.2006.05.001

[17] Zhou, W.Q., Nie, M. (2012). Regional differences in the efficiency of industrial carbon emissions in China. The Journal of Quantitative \& Technical Economics, 29(9): 58-70.

[18] Wang, H., Wang, S.Q. (2015). A study on dynamic evolution of industrial carbon emissions performance and its factors in China. China Population Resources and Environment, 25(9): 29-36. https://doi.org/10.3969/j.issn.1002-2104.2015.09.005

[19] Griliches, Z. (1986). Productivity R\&D and basic research at firm level in the 1970's. American Economic Review, 76(1): 141-153.

[20] Zha, J.P., Fan, L.L., Gao, M. (2014). Research on economic performance of industrial carbon emissions of China and its affecting factors. Soft Science, 28(11): 3034

[21] Han, J., Wang, Y., Chen, C.F. (2015). A study on regional differences of industrial carbon emissions performance and its factors in china spatial econometric analysis based on provincial data. Comparative Economic and Social Systems, 2015(1): 30-34.

[22] Zhang, S.L., Yu, H.S. (2015). Spatial econometric analysis of the efficiency of industrial carbon emissions and its influencing factors. Science \& Technology and Economy, 28(4): 106-110.

[23] Zha, J.P., Tang, F.F. (2012). China's industrial carbon emissions performance: Static level and dynamic changes - an empirical analysis based on provincial panel data in China. Journal of Shanxi University of Finance \& Economics, 34(3): 71-80.

[24] Shao, J., Guan, C.M. (2009). Researches on the efficiency of energy use in China's industry sector and analysis on the influential Factors. Economist, 2009(1): 58-65.

[25] Jin, B. Lv, T., Deng, Z. (2011). Transformation and upgrading of China's industrial structure: progress, problems and trends. China Industrial Economics, 2011(2): 5-15

[26] Huang, G.Q., Liu, F.L. (2019). Mechanism of energy consumption structure and carbon emission intensity in Shaanxi Province. Ecological Economy, 35(5): 36-41.

[27] Wang, S.S., Qu, X.E. (2012). Empirical analysis of foreign trade, foreign direct investment and environmental pollution in China. Journal of Dalian University of Technology (social sciences), 33(1): 25-29.

[28] Wang, X.P., Jiang, Y. (2012). Study on total factor energy efficiency and its influencing factors under the constraint of carbon dioxide emission. Soft Science, 26(2): 73-78.

[29] Wang, J.R., Zhang, Y. (2018). Environmental regulation, green technological innovative intention and green technological innovative behavior. Studies in Science of Science, 36(2): 353-360.

[30] Acemoglu, D., Aghion P., Burszlyn, L., Hemous, D. (2012). The environment and directed technical change. American Economic Review, 102(1): 131-166. https://doi.org/10.2307/41408771 